\title{
Surf Tourism and Sustainable Development in Indo-Pacific Islands. II. Recreational Capacity Management and Case Study
}

\author{
Ralf Buckley \\ International Centre for Ecotourism Research, School of Environmental \\ \& Applied Sciences, Griffith University, PMB 50, Gold Coast Mail Centre \\ Southport Q1d 9726, Australia
}

Recreational capacity is a function of the natural and social environment, the activity concerned, and the management regime. Indo-Pacific surf destinations with cheap and open access and no capacity management have experienced crowding, crime, pollution and price collapses. Many island surf breaks can handle only a few surfers at once because of the shape of the reefs. A crowding factor may be conceptualised as the proportion of rideable waves each surfer is forced to cede to another boardrider. Quota management systems using operator permits need to incorporate the complexity of the environment and the industry, but be equitable enough to gain general acceptance, and simple enough to enforce without dispute. Siberut Island in the Mentawai chain near West Sumatra, Indonesia, is covered by dense tropical rainforest which supports a number of endangered species and has been proposed as a Biosphere Reserve. It is also home to indigenous village communities with traditional social and religious practices. This island is subject to commercial logging and plantation agriculture, and tourism seems to be the only politically realistic economic alternative at present. To provide infrastructure for long-term growth in nature and cultural tourism, an immediate source of tourism revenue is needed. The most immediate option seems to be surf lodges on some of the smaller Mentawai Islands, which have already been largely cleared and are already visited by boat-based surf tour operators. Operators will only invest in lodges if they can acquire preferential rights to particular surf breaks. Hence the recreational capacity of the islands for surf tourism must be determined, and allocated between operators through a management system. Relevant data and one management option are presented here.

\section{Introduction and Methods}

The significance, status and sustainability of surf tourism in Indo-Pacific islands are outlined in broad terms by Buckley (2002). This paper examines a specific issue critical to both the industry and its impacts, namely crowding, recreational capacity and capacity management systems. Possible approaches to the determination and allocation of commercial quotas are illustrated with a case study from the Mentawai Islands in West Sumatra, Indonesia. These islands provide an example of the potential role of surf tourism in sustainable development of small island economies, and also of commercial competitive conflicts within the industry.

Data were obtained from two field trips to the area concerned, specifically for this analysis; a mail survey of all commercial surf tourism operators in the 
Mentawai Islands; face-to-face or telephone interviews with some of the principal operators; and websites for these and other operators; and relevant articles in surfing magazines and elsewhere. In addition, the author has over ten years experience of surfing as a personal sport.

\section{Recreational Capacity in Island Surf Tourism}

\section{General issues}

The term 'recreation capacity' was first used several decades ago but fell into disuse (Haas \& Manfredo, 1999; Lime, 1990; Manning, 1999; McCool \& Lime, 2001). It is currently experiencing renewed interest as the ambiguous and ill-defined concept of carrying capacity receives continuing criticism (Buckley, 1999; Lindberg et al., 1997; McCool \& Lime, 2001). Whereas carrying capacity was supposed to reflect some intrinsic property of the environment concerned, recreation capacity is a broader concept which recognises that different forms of tourist activity have different impacts, and that these may be reflected in different management systems. It differs from a quota, which is simply a number used in operational management, in that it is intended to be based on quantifiable characteristics of the system concerned; but this includes the characteristics of tourism as well as those of the ecosystem.

In general, there are three different sets of criteria which may limit recreation capacity, namely environmental, social and economic. These correspond to three different categories of carrying capacity (Buckley, 1999). They are rather different concepts and typically lead to widely differing outcomes. In addition, each has significant technical difficulties in practical application (Buckley, 1999; Lindberg et al., 1997; McCool \& Lime, 2001). Conceptually, environmental approaches are based on measures and thresholds of environmental change associated with tourism and recreation; social approaches are based on the reactions of tourists to other tourists; and economic approaches are based on changes in net revenue, irrespective of environmental impacts or visitor satisfaction.

The issues involved in defining, quantifying and using recreational capacity have been considered in considerable detail for terrestrial protected areas in the USA (Haas \& Manfredo, 1999; McCool \& Lime, 2001; Haas, 2002).

\section{Crowding}

Crowding is a complex social phenomenon with a long history of theoretical and practical study (Manning, 1999:80-121) These studies have examined issues such as conflicts between different user groups; visitor satisfaction; displacement; prior values; and group behaviour in situations perceived as more or less crowded (Manning, 1999). For outdoor recreation or elsewhere, participants' perspectives of crowding depend on individual normative standards, coping behaviours and trade-offs as well as actual conditions at the time (Manning, 1999).

Different outdoor recreation activities use the outdoor physical environment in different ways, and these differences may also influence participant perspectives on crowding. In a large wilderness area, for example, almost all may potentially be available for hikers, though not all areas will be equally attractive. Rock climbers, in contrast, may all congregate at a single set of routes on a single 
cliff, and whitewater boaters at a single set of rapids on a single river. If someone is already climbing a particular route or playing at a particular whitewater rodeo hole, other users have to queue up or abandon the activity at that site, for reasons of safety and physical space as much as satisfaction.

Perceptions of crowding by boaters have been studied on a number of rivers, particularly in the USA (Manning, 1999: 82, 89-92). Most of those studies, however, are for multi-day river-running trips rather than 'park and play' kayaking at particular rapids, which bears greatest similarities to surfing. The discussion here is specific to surfing, which does not previously seem to have been subject to academic study. It is written from a surfer's perspective, and to most surfers would perhaps seem so self-evident as to be barely worth reiterating. Perhaps, however, this introductory case study may provide a basis for more rigorous theoretical analysis in future.

For surf tourism, the waves will still be there irrespective of the number of surfers. Whilst poor environmental management in local accommodation can certainly cause water pollution and other impacts on the natural environment, and interactions between surfers and local residents may cause cultural changes, both of these can be avoided through appropriate planning, design, technology and operational management.

The most limiting factor for recreational capacity in surf tourism is hence a social one, namely the effect of crowding on the surfers themselves. Surfing in most Indo-Pacific island nations is relatively expensive, because the best surf breaks are only accessible in an ocean-going boat. For those surfers who are willing and able to pay the price, the attraction is not simply good waves, but good uncrowded waves. If there are too many surfers in any of these islands, then they will no longer have any competitive advantage over mainland surf destinations.

As with other forms of outdoor recreation, 'use level is not interpreted negatively as crowding until it is perceived to interfere with or disrupt one's objectives or values' (Manning, 1999: 100). Once the number of surfers exceeds the threshold at which the effects of crowding first become felt, however, crowding means that the more surfers there, the less each will be prepared to pay, on average. Market mechanisms alone, however, do not optimise price and numbers. This would only happen in the economic theoreticians' ideal world, if the relation between number and price were simple, fully reversible, and the only factor involved, and if in addition the product of price and number were highest at an intermediate value of each. But none of these conditions is true in the real world, and reliance on market factors alone will almost certainly lead to high numbers, high crowding, low yield and dissatisfied tourists, as has happened at many sites in Indonesia and elsewhere (Raymond, 1998; Wall, 1997).

The reasons for this are as follows. First, surfers do not necessarily have to use commercial surf tour operators to reach most of the Indo-Pacific island breaks. For travellers with enough time, most of these islands can be reached by ferries or fishing boats. Surfers can stay cheaply in island villages, and reach the breaks either by walking or by being dropped off by a local fishing boat and picked up later in the day. Alternatively, groups of surfers travelling together can charter larger fishing boats. These approaches take more time, are less reliable, and carry 
greater health risks than using one of the specialist surf tour operators, but for wandering surfers without the financial resources to use the tour operators, they offer a perfectly feasible and inexpensive alternative in many countries.

The relation between crowding and price is hence very different for the time-rich, cash-poor independent travelling surfers than for the cash-rich, time-poor surfers who travel on the charter boats (Raymond, 1998). If there are no controls on numbers, crowding can increase indefinitely, until only time-rich, cash-poor surfers go there, and all the cash-rich time-poor surfers go somewhere else.

Secondly, once overcrowding has occurred, it is not easily reversible, and certainly not by market mechanisms alone. It is a great deal more difficult to reduce numbers once they are already high, than to keep them low from the beginning. At a number of well-known Indonesian surf breaks, for example, crowding has led to the proliferation of low-standard local accommodation, with inadequate sewerage and waste management (Reeves, 1997; Wall, 1997). Crime and prostitution are also a growing problem at some sites (Reeves, 1997). The waves are still there, but the amenity value is not. Once this situation has been reached, the cash-rich time-poor surfers who are prepared to pay for uncrowded waves, comfortable accommodation, clean water, and low risk of disease and crime, can no longer be attracted back to the crowded sites.

Crowding is not reversible by market mechanisms within the surf tour industry itself, but only by much larger-scale intervention involving planning controls, social change and major capital investment to create, carve out and police a resort enclave where only the resort clients and service staff are permitted. And this, of course, is not a return to the previous conditions, but another and even more irreversible step towards intensive tourism development. Surf tourism, as opposed to private recreational surfing, is still in a fledgling state, and exclusive enclave-style surf resorts are rare.

There are over 100 'surf camps' worldwide (Raymond, 1998), but few of these are resorts, or exclusive. This approach, however, where an individual tour operator can offer largely exclusive access to particular surf breaks, is currently a preferred development model for many island surf destinations.

The progression outlined above is a commonplace feature of tourism destination development in other sectors. One important aspect is that large-scale capital-intensive development requires continuous high occupancy by highpaying customers in order to be commercially viable. This can rarely be supported by a single specialist sector alone, particularly if these visitors will only pay high prices if numbers are low, as in the case of surfing. Resorts developed under these circumstances are therefore under considerable pressure to expand their range of activities to attract more clients, until ultimately they become generalised destination resorts rather than facilities for specialised sport tourism.

\section{Assessing crowding in surfing}

Critical to this entire approach is the question: At what point does a surf break become too crowded? There are apparently no published empirical or theoretical academic studies, and no definitive answer. From the practical perspective of an individual surfer, the author suggests that one good indicator of crowding is the 
ratio of the number of waves which the surfer is in a position to ride, but which are in fact taken or spoilt by someone else, set against the number of waves which that surfer does actually ride. This depends on many factors, including the shape of the break; swell, tide and wind conditions; the consistency of the takeoff zone; the skill of the individual surfer; and the priority system used to determine who takes each wave.

At a long surf break on a good day, several surfers may share a break without ever having to wait for someone else, if each of them can take a wave during the time it takes for the others to paddle back to the takeoff point. If the break is short or there is a long interval between good waves, however, then everyone will have to wait their turn. In general, therefore, on open-access breaks where the surfers do not know each other, there is a universally known rule which gives priority to the surfer taking off on the inside, i.e. closer to the breaking part of the wave. Breaching this rule is known as 'dropping in', is treated as a cardinal sin amongst surfers, and is liable to provoke physical violence. This rule is generally observed, although there are certain disagreements over interpretation, and certain tricks which experienced surfers will sometimes use in order to take a wave without appearing to break the rule. This rule is an excellent example of the normative behaviour described by Manning (1999: 105-10).

At very crowded sites, however, the 'no-dropin' rule breaks down as surfers become too greedy, too confident or too frustrated. The reason is that it is permissible to take off on a wave outside another surfer, if (a) you can see that the other surfer will be unable to make the wave, i.e. will fall off or become irretrievably caught in the broken part of the wave before he or she reaches you; and (b) if you are wrong and he or she does make the wave, you have sufficient space and skill to get off the wave without interfering with their ride. This rule decreases interference between surfers, because they space themselves out along a break to maximise the chance of getting a wave. In fact, surfing at a crowded break is only partly a matter of technical skill: it becomes a complicated game in which surfers position themselves carefully in relation to other surfers as well as the next few waves. Crow ding in surfing, in consequence, may well be an even more complex phenomenon than in other forms of outdoor recreation.

On uncrowded or moderately crowded days this rule works well, particularly for waves which have a series of alternating difficult and easy sections. On very crowded days, it can lead to mayhem as many surfers take off too close to each other on the same wave. In general, however, the standard priority rule means that locals and experts get the best waves, because they know the best takeoff spots and can take off deeper. If some surfers take proportionately more waves, however, others must take proportionately fewer, so the average crowding ratio remains unchanged.

At breaks without open public access, different priority rules are often used. During competitions, when only the competitors are in the water, a special system is used involving a priority buoy. And when a small group of surfers, who all know each other, are surfing a single break, they may agree to take turns so that everyone gets the same number of waves. For example, some surf charter groups use this system, but others do not (author, pers. obs., 1998-2002).

The threshold number at which surfers begin to feel crowded, therefore, will generally be higher on longer breaks, under good conditions, for a group of 
friends surfing together, than the reverse. But this still does not give us a single magic number. During surfing competitions, early heats are generally run with four surfers in the water at once, but later heats are run with only two surfers. Hence crowding can start at a very small number. At some beach breaks where successive sets peak in different places, up to 50 surfers may be scattered along the beach without undue crowding. On a big day at Burleigh Heads, one of the Australian point breaks on the world pro circuit, 20 surfers can take to the water at once with barely any crowding. On a day with smaller and less consistent surf, each of those 20 surfers would like to take the same waves. And sometimes there are well over 100 surfers out at once, leading to extreme and potentially dangerous crowding. At breaks such as these, minor brawls and occasional injuries are not uncommon.

\section{Quotas and permits}

To maintain uncrowded breaks and a high-yielding surf tourism industry, therefore, numbers must be limited from the start; i.e. recreational capacity must be defined on a social basis, namely the response of surfers to crowding, and the area must be managed to maintain numbers within this capacity. Note that this in itself does not dictate or preclude any particular style of transport or accommodation, including small-scale specialist surf lodges or resorts whether budget or up-market; tour boats; or indeed, independent itinerant surfers who make their own local arrangements.

Indeed, it is important for practical implementation that quota and permit systems based on a recreational capacity approach make explicit provision for private recreation by free and independent travellers (FIT's) as well as commercial tourists. Any permit-based management system needs a mechanism to ensure compliance, and this represents a management cost. Arrangements which have general endorsement by users and local residents, who comply with the permit systems voluntarily and also provide voluntary surveillance, hence have significantly lower management costs than arrangements which require external policing. Of course, there is a transitional period during the introduction of any permit or quota system when external surveillance is required, until the system is established and understood by all concerned.

Where quotas and permits have been established for other types of adventure tourism and outdoor recreation, the allocation of quota between commercial tour operators and private individuals has commonly been a major bone of contention. The best-known example is river rafting and kayaking on the Colorado Grand Canyon in the USA (U.S. National Parks Service, 2002). Following a period of crowding, the tour operators introduced an environmental code of conduct; the US National Parks Service enforced this code through park regulations, and introduced a quota, permit and booking system. The bulk of this quota, however, was given to existing raft tour operators, with only a small proportion set aside for private personal trips run by individuals with their own equipment. The result is that whilst places on commercial trips can be purchased at short notice, there is a 15-year waiting list (or longer) for private trips. For the Grand Canyon, recreational capacity is determined by the availability of suitable campsites along the river, a very practical and immediate physical constraint which is not under management control. Hence the private quota cannot be 
increased without reducing the commercial quota, which of course the commercial operators are highly reluctant to accept.

In the Grand Canyon case, private trips follow the same itinerary, use the same equipment, and are subject to the same environmental and other regulations as commercial trips (Grand Canyon Private Boaters Association, 2002). This would not necessarily be the case for independently travelling surfers at many oceanic islands. The lesson for island surf destinations is simply that once recreation capacity has been estimated as accurately as possible, it is wise not to allocate all of that capacity as irrevocable quotas, but to maintain flexibility either by allocating only part of the quota initially, or by establishing from the outset that quota can be reallocated to match future management priorities.

\section{Quota allocation systems}

In addition to the overall allocation of quota between commercial tours and independent travellers, subsidiary mechanisms are needed to allocate quota between operators and individuals in each category. For individual travellers, for example, part of the quota could be made available for advance booking, e.g. by groups who want to travel in their own boats or arrange their own boat charters. The remaining quota could then be held for allocation on the spot to individuals who arrive independently, without a fixed schedule and perhaps without knowing of the existence of the quota system until they arrive.

For the commercial tour operator component, there are two extreme approaches and many possible hybrids or intermediates. At one extreme, the entire quota can be allocated to operators who were already bringing surfers to the area when the quota was introduced, in proportion to the numbers brought by each; a process known as grandfathering. This is the system which was used in the Grand Canyon. For example, since a permit system has been in operation in Indonesia's Mentawai Islands since 1998, quota could be grandfathered to operators in proportion to the number of permits they applied for historically.

At the other extreme, quota can be allocated annually or even monthly through a waitlist, lottery, auction or tender system. Though some national parks do indeed use allocation systems with a very short lead time, this creates major difficulties for tour operators, who typically need to be assured of quota 18 months to 2 years in advance, to give adequate lead time for packaging and marketing. A good example is provided by the mountain gorillas in Uganda, where even large tour operators can typically sell gorilla tours only provisionally, subject to being able to obtain a gorilla watching permit for the period concerned. The only reason they can sell tours under such conditions is that these are the only mountain gorillas in the world: tourists cannot see them anywhere else (Archabauld and Naughton-Treves, 2001). This does not apply for surf tours.

In addition, unless operators have reasonable security over quotas at a particular break or island, they are unlikely to commit significant capital investment. One possibility might be to allocate part of the quota for a substantial period, e.g. 20 years, to operators prepared to undertake capital investment onshore; with the remainder available for bidding by entirely boat-based operators. To provide advance security but still maintain flexibility, one possible mechanism would be to sell quota for a particular year up to five years in advance, but allow it to be traded and re-sold between operators. 
Since the aim of a quota system is to reduce crowding, however, a simple allocation of visitor numbers between operators in each year will be too crude a mechanism; firstly, since operators might crowd all their quota into a short peak-season period, and secondly, since different operators might bring their clients to the same breaks at the same time. What is needed in the island surf destinations is a system which gives operators and clients, as well as independent travelling surfers, a guarantee of uncrowded breaks. Hence it is not enough to determine quota for an entire island or archipelago: a system is needed which restricts numbers at every break, every day.

A system which allocated individual surfer days at individual breaks, especially if these could be allocated years in advance and traded in subsequent years, would be much too complicated to administer in practice. The problem would not be maintaining central records of allocation, since this could easily be computerised: the problem would be in processing applications to acquire and trade quota, issuing proof of quota rights, policing the permit systems on the water, and resolving disputes.

A practical operational system, therefore, needs to balance a range of competing concerns including equity, efficiency, flexibility, administrative feasibility and expense. These differ between countries and places, depending on history, social frameworks, and patterns of visitation by touring surfers. At least initially, therefore, they need to be considered at the scale of individual case studies. One such example is outlined below.

\section{Mentawai Case Study}

\section{The Mentawai Islands}

Indonesia is the best-known, longest-lived and highest-volume developingcountry destination for surf tourism. As places such as Bali have seen their reputations crumble from South Pacific paradise to crime-ridden tourist trap (Wall, 1997), new areas such as Nias have taken over as fashionable surf tourism destinations, until they too have suffered a similar fate.

Latest in this line are the Mentawai Islands off the west coast of Sumatra, the most westerly of the main Indonesian Islands. The Mentawai Islands provide a good example of the development of upmarket surf tourism, and the issues involved for tourism entrepreneurs, local communities and sustainable development. Here, therefore, this paper examines the current status of tourism in the Mentawais with particular reference to surf tourism; and the factors which may determine whether or not it follows the same path as other Indonesian surf tourism destinations.

The Mentawai Islands lie along a curving diagonal line between $98^{\circ} 55^{\prime} \mathrm{E}, 1^{\circ}$ $20^{\prime} \mathrm{S}$, and $100^{\circ} 20^{\prime} \mathrm{E}, 3^{\circ} 00^{\prime} \mathrm{S}$. The four main islands are Pulau Siberut in the northwest, Pulau Sipura and Pulau Pagai Utara in the centre, and Pulau Pagai Selatan in the southeast (Persoon \& van Beek, 1998). There are many smaller islands. The smallest islands are reef islets scarcely above sea level, most of them long since cleared and planted with coconuts. The smaller islands, and the coastline of the larger islands, are occupied by coastal villages which rely principally on a traditional fisheries economy. 
There are at least 30 surfable breaks in the Mentawais (Great Breaks International, 2001; Indies Trader, 2001; Surf Travel Company, 2001), and most of them are potentially surfable every day of the year, though better at some seasons than others. Currently, there is an effective surfing season of about 30 weeks per year.

Pulau Siberut, largest of the Mentawai Islands, is a mountainous baserock island about the size of Bali (Hardjono, 1991). It supports a large number of plant, bird and mammal species of major conservation value. The whole island has been recommended as a UNESCO-MAB Biosphere Reserve (Sproule \& Suhandi, 1999). To date, however, only a relatively small area is protected, as Siberut National Park (Mitchell, 1982; Persoon \& van Beek, 1998; WWF, 1980). Much of the island has already been logged, and this is continuing (Indonesia, Ministry of Forestry, 1995). Most recently substantial areas have been cleared for oil-palm plantations (R. Cameron, pers. comm., 2001). The coastal areas and smaller reef islands have been planted with coconuts for copra. Despite these changes, the Mentawai Islands are highly scenic, and less modified than much of Indonesia. The mountainous forests of inland Siberut are occupied by a people with different origins, language and lifestyle, with traditional religious practices which in themselves form a cultural tourism attraction (Persoon \& van Beek, 1998).

\section{Tourism in the Mentawais}

Internationally, Siberut has been a destination for special-interest tourists attracted by the culture of the indigenous Siberut people. Their lifestyle and healing practices have been popularised through books and television documentaries, and various local entrepreneurs from Bukittingi and Padang, the nearest ports in West Sumatra, take backpackers to visit the villages (Persoon \& van Beek, 1998). They travel to Siberut by ferry, hike to the villages and stay in their hosts' own homes. Siberut's diverse and unusual bird, butterfly and mammal fauna, which includes the endangered Kloss Gibbon and other monkey species (Whitten, 1982), provides an additional attraction.

There are more than 30 traditional villages on Siberut, each with 50-100 uma, or 'large houses' and 150-200 sapou or 'small houses'. The villages are also classified into an official system of kampungs for government purposes. In southern Siberut there are a dozen traditional villages within range of trekkers, and about 50 umas are visited regularly (J. Juniatur, pers. comm., 1999).

The number of tourists visiting these villages can be estimated with reasonable accuracy because the only access to Siberut, other than charter surf and dive tours which generally do not include village trekking, is via a single large ferry which runs from the mainland twice a month. Foreign trekkers using the ferry are recorded (J. Juniatur, pers. comm., 1999). Their guides are not, but typically there are one or two guides for every group of five to 10 trekkers. Most of these visitors, mainly young backpackers, go on 5 to 10-day treks where they visit several villages and spend a few days in each (J. Juniatur, pers. comm., 1999).

In 1998, ferry records indicate that approximately 1000 overseas tourists and their local guides visited Siberut, representing 5000-10,000 visitor nights in the villages. Note that this represents about half of the total visitor arrivals on Siberut as reported by Sproule and Suhandi (1999), because the total also includes Indonesian and business visitors. Since almost all the trekking takes place during a 
4-month season, this suggest that on average there are about 60 trekkers staying in village houses every night during that season. Local reports (J. Juniatur, pers. comm., 1999) indicate that substantial cultural impacts have already occurred and are continuing, and that current levels of tourism may already exceed recreational capacities based on cultural impact measures.

Currently, these guided treks do not have a high yield in international terms, though they are highly profitable for the local guides from Bukittingi and Padang. Typically, these guides pay the villagers about 30 cents per person per night, whilst charging trekkers about 50 times this amount. Each guide generally leads a group of 5-10 trekkers, who pay around US $\$ 100$ per person for a 7-day trek (Persoon \& van Beek, 1998). Ferries, boats, porters, food, etc. costs about US\$25-30 per person, with the guide making about US\$70-75 per person, or around US\$500 per trip. Of this, they pay the villagers US\$2.20 per group per night, i.e. US\$16 per trip shared between several umas (J. Juniatur, pers. comm., 1999).

Since the villages are only accessible to relatively fit and adventurous tourists prepared to trek through muddy forests and sleep in village huts, tour prices may well be limited by the financial capacity of the young backpacker market. A few of the trekkers are over 50 or even 70 years old, but most are young (Sproule \& Suhandi, 1999). The other islands in the Mentawai chain are not currently visited by tourists except for surfers, who are generally welcomed by local villages.

The Provincial Government of West Sumatra is keen to promote tourism, but anxious to avoid the high-volume, low-budget, low-yield tourism industry which has grown in other parts of Indonesia, notably Bali (Wall, 1997). Local culture, rural agricultural landscapes, religious buildings and practices, and beaches and surf are the main tourist attractions throughout Indonesia, and if West Sumatra wishes to establish a higher-yielding tourism product it must differentiate itself from the rest of the country (Persoon \& van Beek, 1998).

The province has taken several steps towards the promotion of adventure tourism as a key element in its regional tourism strategy. These have been international hang-gliding and parapente championships near Padang, and several of the West Sumatran rivers are visited by whitewater rafters and kayakers.

The Mentawai Islands provide a leading opportunity for the Province, as they can be marketed as uncrowded and unspoilt. Currently, the Mentawais have little or no tourism infrastructure. The Mentawai surf breaks are much less visited than more accessible and better-known Indonesian breaks at Grajagan, Lombok and Nias, which now have a reputation as crowded, unhygienic, and subject to crime (Reeves, 1997). The Mentawai Islands can be promoted as an icon destination, but only as long as tourism is managed for low volume and high yield value of the islands for tourists.

The key to this strategy is active management of tourist numbers, activities and infrastructure, as well as other land uses, in the Mentawai Islands. Without this, its attractions will quickly become crowded and degraded, and there will be no particular reason for tourists to visit (Persoon \& van Beek, 1998). Of course, managing tourism is not the only consideration. If the Mentawai marine and terrestrial ecosystems and human societies are degraded by other land uses, their value for tourism will be decreased accordingly. Wildlife, birdwatching or forest 
ecotourism potential, for example, could quickly be destroyed if remaining forests are damaged by logging or agriculture; and dive tourism is highly susceptible to damage to the marine environment from commercial fishing or marine pollution.

For surf and cultural tourism in the Mentawais, however, the most critical issue is management of the tourism industry itself. For these sectors in particular, therefore, the economic success of the tourism industry depends on identification of maximum recreation capacity for a well-planned industry employing best-practice environmental management techniques; measures to maintain the level of recreational activity, including both private recreation and commercial tourism, within that capacity; and measures to ensure that the industry is in fact well planned and structured, and does in fact adopt best-practice environment management.

\section{Surfing recreational capacity}

Almost all the surf breaks in the Mentawais are reef breaks where there is relatively little room for error. A few have multiple takeoff zones, but most have only one. The first effects of crowding, in that surfers cannot take every wave they might like to, may be noticeable with as few as $2-5$ surfers in the water. A reasonable recreational capacity, in the sense that crowding does not unduly affect surfers' enjoyment of the break, is probably one boatload at any given time, i.e. 510 surfers in the water at any one break. Indeed, if the opportunity exists, a boat with more than 10 surfers might well drop half of them off at one break and the other half at another.

Note that these are not atypical figures for island reef breaks elsewhere. At some of the surf breaks in Samoa or the Maldives, for example, crowding becomes apparent with as few as 5 surfers in the water at once (author, pers. obs. 2001-2002).

Not all the breaks in the Mentawai Islands are of equal quality, and not all work at the same time (Table 1 ). The tidal range is relatively small, so most breaks can be surfed at any time of tide as long as the swell height is not too low. For most breaks, however, the consequences of wipeout are more serious at low tide, when many of the waves break onto dry exposed reefs. In addition, most of the breaks work well only in off-shore winds or calm conditions, which are more common at dawn and dusk than midday. For an extended surf trip, exposure to sun also becomes a limiting factor, so that surfers may choose to avoid the midday period.

The recreational capacity of the Mentawais for surfing is therefore determined by the minimum number of surfable breaks under the least favourable common weather conditions. Note that in a typical 10-14 day trip, surfers might well anticipate a few days of unsurfable conditions, and would generally be happy to go fishing, snorkelling, or hiking on the islands during such layover days. They would be highly dissatisfied with an extended run of unsurfable days, however, particularly if some breaks were working, but not the ones they were visiting.

Principal surf breaks, and the wind conditions under which they are surfable, are listed in Table 1 . Note that only 5-10 of these are of the highest quality, the named breaks which attract surfers to the Mentawais; and under most conditions, 
Table 1 Mentawai Islands surf breaks

\begin{tabular}{|c|c|c|c|c|c|c|c|}
\hline Break & Island & Base & Type & Swell & Size & Wind & Rank \\
\hline Paserakat & Paseratat & Sand & L\&R & W & $1-3 m$ & NE-SE & $* *$ \\
\hline Sinyau R & Sinyaunau & Reef & Right & $S-W$ & $2-4 m$ & $\mathrm{~N}-\mathrm{NE}$ & $* * * *$ \\
\hline Burgerworld & Koroniki & Reef & Right & SW & $2-4 \mathrm{~m}$ & NW-W & $* * *$ \\
\hline E-Bay & Nyang Nyang & Reef & Left & W & $3-4 \mathrm{~m}$ & S-E & $* * * * *$ \\
\hline Bangbangs & Nyang Nyang & Reef & Left & W & $2-3 m$ & S-E & $* * *$ \\
\hline Nipusie & Nyang Nyang & Reef & Right & S-SW & $1-4 \mathrm{~m}$ & NW-NE & $* * *$ \\
\hline Bank Vaults & Nyang Nyang & Reef & Right & S-SW & $1-4 \mathrm{~m}$ & $\mathrm{~N}-\mathrm{NE}$ & $* * *$ \\
\hline Mainu Left & Mainu & Reef & Left & W & $2-4 \mathrm{~m}$ & SE-E & $* * *$ \\
\hline Hideaways & Mainu & Reef & Right & S-SW & $3-4 \mathrm{~m}$ & W-S & $* *$ \\
\hline Pearlers Peak & Katurei & Reef & L\&R & S-SW & $3-4 \mathrm{~m}$ & NE-N & $* *$ \\
\hline Boat Pass & Tudanging & Reef & Right & S-SW & $3-4 m$ & S-SW & ** \\
\hline Rifles & Karamajet & Reef & Right & S-SW & $1-3 \mathrm{~m}$ & NW-W & $* * * * *$ \\
\hline Four Bobs & Karamajet & Reef & Right & S-SW & $2-4 m$ & NW-W & $* * *$ \\
\hline Rubber Duck & Karamajet & Reef & L\&R & S-SW & $2-4 m$ & NW-W & $* * *$ \\
\hline No-Kanduis & Karamajet & Reef & Left & SW & $2-4 m$ & S-SE & $* * * *$ \\
\hline John Kandi L & Penanggalan & Reef & Left & S-SW & $1-2 \mathrm{~m}$ & NW-W & $* *$ \\
\hline Chubies & Penanggalan & Reef & Right & S-SW & $2-3 m$ & NW-W & ** \\
\hline Ice Land & Pototogat & Reef & Left & SW & $1-4 \mathrm{~m}$ & NE-E & $* * * *$ \\
\hline Kantrels & Pototogat & Reef & Right & W & $3-4 \mathrm{~m}$ & NE & $* *$ \\
\hline Transits & Silabok & Reef & Right & W & $3-4 \mathrm{M}$ & SE & ** \\
\hline Suicides & Sipura & Reef & Left & SW & $2-4 \mathrm{~m}$ & E-SE & $* *$ \\
\hline Telescopes & Simapadegat & Reef & Left & SW & $2-4 \mathrm{~m}$ & E-SE & $* * * * *$ \\
\hline Scarecrows & Pitoyat & Reef & Left & SW-W & $1-4 \mathrm{~m}$ & SE & $* * *$ \\
\hline Simailupa & Simailupa & Reef & Left & SW & $2-4 \mathrm{~m}$ & NE-E & ** \\
\hline Bombie & Trait & Reef & L\&R & SW & $2-4 \mathrm{~m}$ & NE-E & $* *$ \\
\hline The Ledge & Siduamata & Reef & Left & SW & $2-3 m$ & $\mathrm{~N}-\mathrm{NW}$ & $* * *$ \\
\hline Duamata R & Siduamata & Reef & Right & S-SW & $2-3 m$ & NW-N & $* *$ \\
\hline Lances Left & Sibesua & Reef & Left & W-S & $2-3 \mathrm{~m}$ & NE-S & $* * * * *$ \\
\hline Bintangs & Sibesua & Reef & Right & W-S & $2-4 m$ & NE-S & $* *$ \\
\hline $\mathrm{HT}^{\prime} \mathrm{s}$ & Katiet & Reef & Right & S-SW & $2-4 \mathrm{~m}$ & NW-S & $* * * * *$ \\
\hline $\mathrm{ET}^{\prime} \mathrm{s}$ & Batukinapat & Reef & Right & S-SW & $1-3 m$ & NW-W & $* * *$ \\
\hline Waterfalls & Takarimau & Reef & Left & W-S & $2-4 \mathrm{~m}$ & E-SE & $* * * *$ \\
\hline Crusoes & Batumalai & Reef & Right & W-S & $3-4 m$ & NE-S & $* * *$ \\
\hline Maccas & Pasangan & Reef & Left & SW & $2-4 m$ & NE-S & $* * * * *$ \\
\hline
\end{tabular}


Table 1 (contd)

\begin{tabular}{|l|l|l|l|l|l|l|l||}
\hline Break & Island & Base & Type & Swell & Size & Wind & Rank \\
\hline Occy's R & Pasangan & Reef & Right & S-SW & $3-4 \mathrm{~m}$ & N-NE & $* *$ \\
\hline Lost Left & Sabeoguguk & Reef & Left & SW & $2-3 \mathrm{~m}$ & NE & $* *$ \\
\hline Rags Left & Bitojat & Reef & Left & W & $2-4 \mathrm{~m}$ & S & $* * * * *$ \\
\hline Rags Right & Bitojat & Reef & Right & S-SW & $2-4 \mathrm{~m}$ & N-NW & $* * * *$ \\
\hline Thunders & Sibigau & Reef & Left & All & $1-3 \mathrm{~m}$ & SE-S & $* * * * *$ \\
\hline Thunders R & Sibigau & Reef & Right & S-SW & $2-4 \mathrm{~m}$ & N-NW & $* * *$ \\
\hline Libuat & Libuat & Reef & Right & All & $1-3 \mathrm{~m}$ & N-NE & $* * * *$ \\
\hline Turuns & Silau & Reef & Left & SW & $2-4 \mathrm{~m}$ & S & $* * * *$ \\
\hline Kimbies & Tio & Reef & Left & W & $3-4 \mathrm{~m}$ & S-SW & $* * *$ \\
\hline Screamers & Sibarubaru & Reef & Left & W & $3-4 \mathrm{~m}$ & E & $* * *$ \\
\hline Discos & Siatanusa & Reef & Left & S-SW & $2-4 \mathrm{~m}$ & E & $* * * * *$ \\
\hline The Hole & Siumang & Reef & Left & S-SW & $2-4 \mathrm{~m}$ & SE & $* * * * *$ \\
\hline Lighthouse L & Simonga & Reef & Left & S-SW & $2-4 \mathrm{~m}$ & SE & $* * *$ \\
\hline Lighthouse R & Simonga & Reef & Right & S-SW & $2-4 \mathrm{~m}$ & W-SW & $* * * *$ \\
\hline Sanding & Sanding & Reef & Right & S-SW & $1-4 \mathrm{~m}$ & NW-W & $* * *$ \\
\hline
\end{tabular}

Data from R. Cameron GBI, and author's observations. Rank: ${ }^{* * * * *}=$ best.

not all of these will be surfable. They have names such as Lighthouse, Thunders, Rags, Maccas, HT's, Lance's Lefts, Telescopes, No-Kanduis and Rifles .

Conditions are most limiting during northerly winds, when only a few breaks in each geographical zone are functioning. Based on this analysis, the recreational capacity of the entire Mentawais Islands chain would seem to be around 10 boatloads of 10 surfers each, i.e. about 100 surfers. In addition, another 20-30 surfers travelling independently could probably be accommodated on these and other breaks. In recent years, up to 18 commercial surf charter boats were operating simultaneously in the Mentawais, and the effects of crowding were very evident (P. King, pers. comm., 1999).

One hundred surfers each day corresponds to about 20-25,000 surfer days per year, for a fully booked 30-week season. Currently, boat-based surf tour operators take about 1500 surfers per year to the Mentawais, corresponding to about 15-20,000 surfer days per year. Hence it would appear that existing operators have effectively saturated the recreational capacity of the Mentawai surf breaks. Some operators, indeed, consider that the area is already past saturation point ( $R$. Cameron, pers. comm., 2000).

\section{Prices, cashflows and investment}

Current prices for Mentawai surf tours range from US\$120-275 per person per day for the boat-based section, but these are held down by strong competition between operators. If local internal competition were reduced through a 
recreational capacity management system so that the Mentawai surf tour operators were only competing against surf tour operators elsewhere in the world, then prices of US\$200-300 per person per day could probably be maintained, with the higher prices during the peak season. For 200 days operation per year, this suggest a total gross income of US\$5 million per annum for the Mentawai surf tour industry.

The precise cost of constructing and operating an upmarket surf resort depends on many factors and is commercially confidential to individual operators. A beach resort at Broken Head on Australia's central east coast, however, had an estimated construction cost of AU\$2.64 million in 1998, for a design incorporating 21 individual houses and a range of central and management facilities, for 56 people in all (BHCF, 1998). Allowing for inflation and exchange rates, this corresponds to about US\$1.63 million in 2002, for a development which is closely similar in design and scale to the most upmarket of the smaller island surf resorts.

Hence even at a relatively small profit margin, a gross income of US\$5 million per annum would seem to be sufficient to support capital investment in several small but relatively upmarket surf lodges or surf resorts on particular islands. Note that as well as actual construction costs, marketing, transport, etc. this investment would necessarily include considerable expenditure in mosquito control, to avoid guests contracting malaria or dengue fever; on waste management, particularly sewage treatment, to avoid the unhygienic conditions which have become such a problem with unplanned village accommodation; and on training for local residents seeking employment.

These lodges or resorts can also act as a base for fishing, diving, cultural and nature tours run in parallel with surf tourism, either by the same tour operators, or by separate companies which use the surf resorts for accommodation and a transport and logistics base.

\section{Capacity management systems}

A capacity management system for surf tourism in the Mentawai Islands needs to recognise the complexities of the environment and the industry. Different breaks work better under different weather conditions, and hence at different times of year. The Mentawais span a considerable geographical area, and it takes time for a boat to travel from one break to another. Boats currently operating in the Mentawai Islands can travel quickly between adjacent breaks, and overnight from one end of the Mentawais to the other (Great Breaks International, 2001; Surf Travel Co., 2001; Indies Trader, 2001). If on-shore surf lodges or resorts are developed on some islands, they will need preferential access to the adjacent breaks. Because of the access logistics, surfers do not visit the Mentawais for a single day, but typically for 10-11 days; and except for a few independent travelling surfers, they do not visit individually but in boatloads, with each boat typically carrying 6 to 10 surfers and occasionally more.

Because of this complexity, a simple annual quota of surfer days for each commercial tour operator would not address the critical issue of crowding at particular breaks on particular days. A system which allocated individual days at specific breaks to specific operators, however, though feasible in theory, would probably be too cumbersome and contentious in practice. As with any recreational capacity management system, a system for the Mentawais needs to 
be operationally simple and generally accepted in order to work in practice. A system is therefore required which is intermediate between a broad annual quota and individual surfer days for particular breaks.

An approach suggested by one of the operators (GBI, 1999), is to allocate different groups of breaks to different individual operators or syndicates of operators in such a way that each operator has access to a range of breaks in different parts of the Mentawai Islands, which they can use preferentially at different times of year. Under some weather conditions, i.e., all the operators may want to take their clients to breaks on the southwestern side of the islands in the southern part of the Mentawai Islands; whereas at other times they may all wish to surf at breaks on the southeastern side of the islands in the northern part of the Mentawai Islands.

Under the system proposed by GBI, there would be four operator syndicates, some of which might contain only a single operator, and each of these would be granted exclusive access to five groups of adjacent breaks, one group in each of five geographical zones spread along the length of the Mentawais. Hence each operator syndicate would have exclusive access to at least one break in each major region of the Mentawais.

Clearly, this favours existing operators over potential future operators; but of course, it is the existing operators who have invested in exploring the Mentawais and marketing them to the international surfing community to date. If all the breaks were allocated to existing operators initially, then future operators could only obtain access by buying existing operators out of established syndicates.

Alternatively, the West Sumatran Government or its management agency for the Mentawais might choose to allocate rights to different groups of breaks gradually, over a period of several years or longer, so that some syndicates were established immediately, and others after the system had already been tested. In addition, future operators might be able to buy into existing syndicates without displacing existing members, if the latter were not using their full quotas.

Whether or not a system such as this is implemented in practice is essentially a political rather than a technical issue; and currently, rather a cloudy one. The other two major surf tourism operators in the Mentawai Islands apparently do not endorse this proposal, and each is pursuing an independent strategy.

\section{Conclusions}

Surf tourism in Indo-Pacific islands provides an excellent testbed for recreational capacity approaches to the management of commercial operations in the NEAT (Nature, Eco \& Adventure Tourism) sector, for the following reasons. (1) Client response to crowding provides a very direct, immediate and financially measurable indicator of capacity. (2) At many Indo-Pacific island tourism destinations capacity for surf tourism is low and can be reached very rapidly. (3) The first limiting constraint on capacity is an internal social factor amongst clients, and on some islands at least, this capacity can be reached or exceeded before irreversible damage is inflicted on the natural or cultural environment of the islands concerned. (4) There are many Indo-Pacific islands which are about equally attractive as surf tourism destinations and compete directly for tourists, but 
which differ significantly in regards to relations between surf tour operators, local access to surf breaks, and approaches to capacity management.

Surf tourism is by no means the only form of tourism on most of these islands, but in many cases it is a leading component since it can bring relatively high-paying tourists to areas with little or no fixed infrastructure. Surf tourism hence has the potential to play a key role in providing a cash flow which can fund tourism infrastructure to support the development of broader nature, adventure and cultural tourism sector in these islands.

Surf tourism in small Indo-Pacific islands, however, is particularly vulnerable to crowding and downmarket competition, as has happened in other developing-country surf tourism destinations. Identification and management of recreation capacity is hence particularly critical to maintain an economically, social and environmentally sustainable tourism industry.

Surf tourism in Indonesia's Mentawai Islands exemplifies all of the above. The surf is the only internationally exclusive and globally competitive tourism attraction on the smaller Mentawai Islands. Cultural tourism provides an additional option on Siberut. For both cultural-impacts and on-ground logistic reasons, it would be much more difficult to develop high-yield low-impact resorts based on cultural tours than on surf tours. Tourism is important for both the peoples and natural environment of the Mentawai Islands, because it provides much better prospects for funding educational and health development with less damage to vegetation, wildlife and water quality, than other economic sectors such as forestry or agriculture.

There is currently fierce competition between major surf tourism operators. This is commonplace for private-sector entrepreneurs in tourism as in other industries. Capacity management systems can generally only be imposed, however, when a single agency controls access. This may be either a government body or a private landholder, as long as it has effective control. Groups of competing operators can rarely agree either on the total quota or on its allocation, without ratification and implementation by an overriding government agency. This operator-driven approach has succeeded occasionally, but perhaps only where operators perceived competition from new entrants as a greater threat than competition with other existing operators. Where operators are competing actively for control and market dominance, as in the Mentawais at present, they are unlikely to reach agreement. And if there is no government agency with the interest, resources and clear authority to impose and implement a capacity management system, then visitor numbers and impacts are likely to continue growing, with adverse consequences for operators and host communities alike.

If tourism is to develop in the Mentawais, the analysis above indicates that its best prospect may well be the establishment of small resorts based on the surf tour industry, which can spearhead expansion into other types of tourist activity, including the potentially much larger nature, eco and adventure tourism sector. The conditions required to attract investment in surf resorts, however, can probably only be provided if these resorts' clients have a guarantee of access to uncrowded breaks, and this can only be provided through a management agency and strategy as above.

The recreational capacity of the Mentawai surf breaks is the key to this management strategy, and hence to the entire tourism industry in the Mentawai 
Islands. In the world of practical politics in which we live, it is not too far-fetched to suggest that the recreational capacity of the Mentawai surf breaks is significant for both conservation and social welfare on the entire Mentawai chain.

\section{Acknowledgements}

Information on the indigenous Siberut villages and guided treks was provided by Mr J Juniatur. Detailed data on surf breaks, including that in Table 1, was provided by $\mathrm{Mr} \mathrm{R}$ Cameron. Information on history, current operations, perceived crowding, capacity management options, and business development plans was kindly provided by a number of surf tour operators.

\section{Correspondence}

Any correspondence should be directed to Ralf Buckley, International Centre for Ecotourism Research, School of Environmental and Applied Sciences, Griffith University, PMB 50, Gold Coast Mail Centre Southport, QLD 9726, Australia 4217 (r.buckley@mailbox.gu.edu.au).

\section{References}

Archabauld, K. and Naughton-Treves, L. (2001) Tourism revenue-sharing around national parks in western Uganda: Early efforts to identify and reward local communities. Environmental Conservation 28, 135-49.

Broken Head Coastal Foundation Pty. Ltd (1998) Development Application. Lot 2 and 5 DP729112. Submission to Byron Shire Council, Lennox Head, Geolink P/L.

Buckley, R.C. (1999) An ecological perspective on carrying capacity. Annals of Tourism Research 26, 207-10.

Buckley, R.C. (2002) Surf tourism and sustainable development in Indo-Pacific islands: I. The industry and the islands. Journal of Sustainable Tourism (in press).

Grand Canyon Private Boaters Association (2002) Grand Canyon Private Boaters Association. On WWW at www.gcpba.org. Accessed 14.8.02.

Great Breaks International (1999) Submission to Indonesia, Ministry for Tourism. KANWIL, Padang.

Great Breaks International (2001) On WWW at www.greatbreaks.com.au and www. mentawai.org. Accessed 1.10.01.

Haas, G. (2002) Visitor Capacity on Public Lands and Waters: Making Better Decisions. USDI, Washington DC.

Haas, G. and Manfredo, M. (eds) (1999) Abstracts, Recreational Capacity Conference, Snowmass CO. Fort Collins: Colorado State University.

Hardjono, J. (1991) Indonesia Resources, Ecology and Environment. Singapore: Oxford.

Indies Trader (2001) On WWW at www.indiestrader.com. Accessed 1.10.01.

Indonesia, Ministry of Forestry (1995) Siberut National Park Integrated Conservation and Development Management Plan. Report of ADB Loan 1187-INO (SF), Biodiversity Conservation Project in Flores \& Siberut. Jakarta: Asian Development Bank.

Lindberg, K., McCool, S. and Stankey, G. (1997) Rethinking carrying capacity. Annals of Tourism Research 24, 461-4.

Lime, D.W. (ed.) (1990) Managing Americas Enduring Wilderness Resource. St Paul: University of Minnesota.

McCool, S.F. and Lime, D.W. (2001) Tourism carrying capacity: Tempting fantasy or useful reality? Journal of Sustainable Tourism 9 (5), 372-88.

Manning, R. (1999) Studies in Outdoor Recreation (2nd edn). Corvallis: Oregon University Press.

Mitchell, A. (1982) Siberut Nature Conservation Area (West Sumatra) Management Plan, 19831988. Bogor: WWF. 
Persoon, G. and van Beek, H.H. (1998) Uninvited guests: Tourists and environment on Siberut. In G. Persoon, H.H. van Beek and V. King (eds) Environmental Challenges in South-East Asia (pp. 317-41). Copenhagen: Nordic Institute of Asian Studies.

Raymond, B. (1998) Untitled. Australian Surfers Journal (Summer).

Reeves, P. (1997) Life at Lagundi in the 1980s. Surfers Journal (Summer).

Sproule, K. and Suhandi, A. (1999) Siberut Island Nature Conservation Area, Indonesia. On WWW at http:/ / www.podi.com/ecosource/ecotour/research/stats.htm.

Surf Travel Company (2001) On WWW at www.surftravel.com. Accessed 1.10.01.

US National Parks Service (2002) Grand Canyon National Park. On WWW at www.nps. gov/grca/grandcanyon. Accessed 14.8.02.

Wall, G. (1997) Bali and Lombock: Adjacent islands with contrasting tourism experiences. In G. Shaw and A. Williams (eds) Island Tourism (pp. 268-80). London: Pinter.

Whitten, G. (1982) The Gibbons of Siberut. London: Dent.

Worldwide Fund for Nature (WWF) (1980) Saving Siberut. A Conservation Master Plan. Bogor: WWF, Indonesia programme.

\section{Personal Communications}

J. Juniatur is at Universitas Sumatera Utara

P. King owns and works for the Surf Travel Company

R. Cameron owns and works for Great Breaks International 